\title{
Freeze-and-share: New schemes, old ethics?
}

\section{Congelar-y-compartir: ¿nuevos esquemas, vieja ética?}

\author{
Rune Klingenberg* \\ Department of Communication and Arts, Philosophy and Science Studies, Roskilde University, Roskilde, Denmark
}

\begin{abstract}
At some fertility clinics, women can get a discount on egg freezing provided that they agree to share a portion of their eggs with another woman or couple undergoing fertility treatment. Some critics have argued, however, that this practice is no different from traditional egg sharing (TES) schemes, where women can get a discount on fertility treatment provided that they agree to share a portion of their eggs with another woman or couple undergoing fertility treatment, a practice that has been widely criticized on the grounds that it harms donors, commodifies the human body, pressures women into giving away their eggs, and exploits those who cannot otherwise afford treatment. In this paper, I discuss how the practice of freeze-and-share (FAS) schemes compares morally to TES schemes, and I argue that although these practices may appear to be morally on par, that is, not the case on closer inspection. I also tentatively suggest that although FAS schemes can be considered more exploitative than TES in one sense, such schemes are nevertheless still easier to justify.
\end{abstract}

Key words: Egg sharing. Egg freezing. Egg donation. Commodification. Consent. Exploitation.

\section{Resumen}

En algunas clínicas de fertilidad, las mujeres pueden obtener un descuento en la congelación de óvulos si comparten una porción de sus óvulos con otra mujer o pareja en tratamiento de fertilidad. Sin embargo, algunos críticos han argumentado que esta práctica no es diferente de los esquemas tradicionales de intercambio de óvulos, donde las mujeres pueden obtener un descuento en el tratamiento de fertilidad si comparten una porción de sus óvulos con otra mujer o pareja, una práctica que ha sido ampliamente criticada sobre la base de que daña a las donantes, mercantiliza el cuerpo humano, presiona a las mujeres para que regalen sus óvulos y explota a quienes de otra manera no pueden pagar el tratamiento. En este artículo analizo cómo la práctica de los esquemas de congelar y compartir se compara moralmente con los esquemas tradicionales de intercambio de huevos, y sostengo que, aunque estas prácticas pueden parecer moralmente a la par, ese no es el caso después de una inspección más cercana. También sugiero tentativamente que, aunque los

\footnotetext{
Correspondence:

Rune Klingenberg

E-mail: ruklha@ruc.dk

Date of reception: 29-10-2020

Date of acceptance: $10-11-2020$

DOI: 10.24875/BUP.M20000003 E-mail: ruklha @ ruc.dk DOI: 10.24875/BUP.M20000003 www.bioethicsupdate.com
2395-938X / @ 2020 Centros Culturales de México, A.C. Published by Permanyer. This is an open access article under the license CC BY-NC-ND (http://creativecommons.org/licenses/by-nc-nd/4.0/).

Disponible en internet: 21-05-2021 BIOETHICS UPdate 2021;7(1):71-81 www.bioethicsupdate.com
article under the license
} 
esquemas de congelar y compartir pueden considerarse más explotadores que el tradicional intercambio de huevos en un sentido, tales esquemas son, sin embargo, más fáciles de justificar.

Palabras clave: Compartición de óvulos. Congelación de óvulos. Donación de óvulos. Mercantilización. Consentimiento. Explotación.

\section{Introduction}

Should fertility clinics be allowed to offer women a discount on egg freezing in exchange for some of their eggs? In recent years, many fertility clinics have started offering women fertility preservation based on cryotechnology, giving them the opportunity to freeze their eggs while they are young and healthy and then use those eggs to become pregnant later in life. Moreover, since this procedure is rather expensive, some clinics (e.g., London Egg Bank) have started freeze-and-share (FAS) schemes, where women can get a discount on egg freezing provided that they agree to donate a portion of their eggs to another woman or couple undergoing fertility treatment.

There are a couple of advantages to such schemes from a moral point of view. The first concerns the fact that FAS makes egg freezing available to a much larger segment of the population. To the extent that egg freezing is a benefit, FAS simply enables more people to enjoy this. This ties in well with the second advantage, having to do with the financial expenses of egg freezing (that is, inequality). As such expenses are relatively high; egg freezing is often condemned as an elitist project, primarily benefitting the most well off in society. Egg freezing often costs around 15-20.000 USD per cycle, and women opt for two cycles on average. FAS could potentially alleviate this concern by widening the circle of potential freezers directly, as well as bringing the costs down over time. As is common with new technology, it usually becomes cheaper over time and through prevalence, as the technology becomes more developed and the economy of scale allows for price reductions. The third advantage to FAS from a moral point of view is that FAS can potentially help increase the availability of donor eggs for fertility treatment or research, which are currently in short supply in most parts of the world ${ }^{1-3}$.

Despite these apparent advantages of FAS; however, some critics have advanced the view that FAS is no different from traditional egg sharing (TES) schemes, a practice that has historically seen a great deal of moral opposition ${ }^{4}$, despite having advantages similar to those of FAS. In TES, women get a discount on fertility treatment provided that they agree to share a portion of their eggs with another woman or couple currently undergoing fertility treatment. Such schemes have remained highly morally controversial on the grounds that they harm donors, for example ${ }^{5}$ commodify the human body ${ }^{6}$, pressure women into giving up their eggs ${ }^{7}$, and exploit the worst off see example $^{8}$. In fact, TES is considered so morally controversial that it is only practiced in a small handful of countries, such as the UK and Poland?

Compared to TES, however, not much have been written on the moral merits of FAS, perhaps because the practice is relatively new; perhaps because it is (falsely) assumed to be morally on par with TES. This paper aims to remedy this situation. More specifically, I will discuss whether and to what extent traditional criticisms of TES also apply to FAS. As I will show, the two practices are much more morally different than they may appear from the outset, and I will tentatively suggest 
that although FAS in one sense can be considered more exploitative than TES, it still appears to be easier to justify, as FAS is arguably less harmful to donors and less compromising in terms of their autonomy.

Before we get to that, however, a couple of clarifications are in order. The first concerns the notion of TES. What I am concerned with here are solely schemes that involve reduced treatment costs in exchange for human eggs, and not for example, schemes that involve reduced treatment costs due to two (or more) recipients sharing eggs from the same donor (a practice which is also sometimes referred to as egg sharing). Similarly, I will not discuss practices where women freely share surplus eggs left over from fertility treatment (a practice also sometimes referred to as egg sharing).

The second clarification worth noting is that the following does not concern the moral merits of egg freezing in itself, only the practice of giving women a discount on egg freezing in exchange for some of their eggs. Egg freezing, at least when done for no obvious medical reason, remains a morally controversial practice for a number of different reasons. For one thing, critics worry that egg freezing may harm future children by promoting current trends of delaying pregnancies, leaving children with parents who have less energy and fewer years to live for a critical discussion of this view see example ${ }^{9,10}$. However, the practice of egg freezing is distinct from the practice of giving discounts on freezing in exchange for eggs. Although the latter inherits any moral problems of the former, as it entails freezing, FAS schemes have their own set of moral issues independent of those entailed by freezing for non-medical reasons. It is these independent moral issues, and not issues concerning egg freezing as such, that I will discuss.

I will do this as follows: In the first section, I discuss whether TES and FAS are morally on par when it comes to harm to donors. In the second section, I discuss whether FAS wrongly commodifies the human body in the same way as TES. In the third section, I discuss whether FAS has the potential to disturb consent to the same extent as TES. In the fourth section, I discuss to what extent FAS might involve exploitation. In the fifth section, I sum up and conclude.

\section{Harm to donors}

One traditional criticism of TES schemes is that such schemes potentially cause harm to donors. For one thing, they leave the donor with less usable eggs than she would otherwise have had access to. Women in fertility treatment may not have that many usable eggs available, and by giving up a portion of their eggs, they reduce their chances of achieving pregnancy. Moreover, donors who end up without achieving pregnancy may be disturbed by the fact that someone else achieved pregnancy with a child genetically related to them ${ }^{5}$. As egg sharing has remained controversial, not many studies are available with regard to such repercussions, but one study from 1997 found that 1 in 11 egg sharers who did not become pregnant experienced such distress ${ }^{11}$.

With regard to the medical risks of undergoing hormonal stimulation and egg retrieval, there is seemingly no difference between the harm caused by engaging in TES and FAS. Although donors engaged in FAS would presumably be younger and thus ceteris paribus better physically able to 
handle the procedure. Moreover, donors engaged in TES may suffer additional harm due to repeated hormonal stimulation, as their eggs are usually not of the same high quality as donors engaged in FAS, who tend to be much younger. By and large, however, these risks seemingly remain the same.

Nevertheless, contrary to donors engaged in TES, donors who engage in FAS are not harmed by having to give up on eggs that could have been used to achieve a pregnancy. To understand why, it is necessary to know a bit about the process of egg retrieval as well as the female reproduction system. When a woman reaches puberty, she will typically have around 300,000 eggs. However, only 300-500 of those will ovulate during her lifetime. Every month, a number of eggs start maturing but only one of them will reach the point of ovulation. The rest are destroyed and absorbed back into the body. When a woman engages in egg retrieval, this process is controlled through hormonal stimulation with the aim of taking out all the eggs before they are destroyed. This is why donors engaged in FAS do not give up on eggs that could have been used to achieve a pregnancy, as all the eggs retrieved would otherwise have gone to waste in a menstrual cycle. This is not the case for donors engaged in TES, as they are currently trying to get pregnant, and usually have fewer eggs left ${ }^{12}$. The eggs that they have to give away are therefore eggs that they could otherwise (at least hypothetically) have used to become pregnant whether TES harms donors can of course be disputed. By engaging in TES, donors typically increase their chances of becoming pregnant, so if they are harmed in this way, it appears to be locally and not globally. In other words, they are seemingly not harmed overall, although they may incur certain costs that donors engaged in FAS do not incur. The point here, however, is not to discuss the moral merits of TES, but rather to discuss whether traditional concerns about TES also apply to FAS. In this particular regard, the answer seems to be negative. That is, donors engaged in FAS typically suffer less harm than donors engaged in TES.

With regard to the potential psychological harm to donors who do not become pregnant, the concern, however, remains that some freezers will end up without becoming pregnant, and that they will suffer distress from the knowledge that there are (or could be) children genetically related to them out there. There is no reason to suppose that this distress would be any less severe for someone engaged in FAS who do not become pregnant, if such distress is caused solely by the fact that there is a child out there, with whom one shares a genetic relation.

However, to the extent that distress is related to regret, there are reasons to assume that donors engaged in FAS will feel less psychological distress, should they end up involuntary childless themselves. As explained above, unlike donors engaged in TES, donors engaged in FAS do not give up on eggs that could hypothetically or realistically have led to a successful pregnancy. Had these women not engaged in FAS, those eggs would have been absorbed into the body. The fact that they engaged in FAS will, therefore, not in any way have reduced their chances of becoming pregnant, on the contrary. It, therefore, seems reasonable to presume that they will feel less regret about having donated some of their eggs earlier in life, should they nevertheless end up not having children themselves. Although this is admittedly speculative, this observation is somewhat supported by findings from Waldby ${ }^{13}$.

In any case, there are good reasons to suppose that distress will be much less frequent. The reason is that many of those who engage in FAS will presumably achieve pregnancy the 
old-fashioned way and thus (perhaps somewhat paradoxically) never return to fertility treatment later in life. Most women who freeze their eggs do so as a back-up plan, should everything else fail ${ }^{14}$. Only few, if any, pursue egg freezing and fertility treatment as their first or second option. In other words, the odds of donors engaged in FAS ending up childless are slim compared to donors engaged in TES, who are undergoing fertility treatment precisely because they have reduced chances of achieving pregnancy.

Based on the above, it seems that TES and FAS are not morally on par when it comes to potential harm to donors. That is, FAS appears to be less harmful because it does not require donors to give up on eggs that they could have otherwise used to become pregnant, which also lessens the risk of later regret. Furthermore, the risk of donors, who end up childless, experiencing psychological distress, is much smaller for donors engaged in FAS than in TES. However, another traditional criticism of TES appears to apply much more straightforwardly to FAS, namely, the worry that egg sharing schemes (traditional or modern) wrongfully commodify human life. This is the subject of the following section.

\section{Commodification}

The second traditional criticism of egg sharing is that giving women a benefit in terms of a discount on treatment in return for their eggs puts a price on something that should not be traded for monetary rewards ${ }^{6}$. This is a charge of (morally wrongful) commodification. Not all commodification is morally wrongful. For instance, it is difficult to see why it would be morally wrongful to put a price on something like a pair of shoes. Indeed, it is a good thing that something like shoes has a price, because this means that people who need shoes are able to buy them. But some people believe that there is something morally wrongful about commodifying the human body or parts of it $\mathrm{t}^{15,16,17}$. The idea, here, is that the human body (and its parts) has inherent value, or worth; it does not (or ought not) have a financial price.

It is difficult to dispute the claim that both TES and FAS involve commodification. In both practices, women or couples are given a benefit (reduced financial cost) in exchange for their eggs. If this is morally wrongful, it goes for both practices. However, on closer inspection, moral objections to commodification come in different forms and, as I will show, not all of them apply equally well to TES and FAS.

Objections to commodification can roughly be characterized as based on either semiotics, corruption, or inequality ${ }^{15,18}$. Semiotic objections concern the meanings of certain things or practices, which are perceived to be threatened by commodification. For instance, it is sometimes held that surrogacy unduly changes the meaning of parenthood. Corruption-based objections are inter alia based on the tendency of commodification to crowd out altruistic practices, which are usually considered more morally valuable than non-altruistic practices. For instance, allowing people to donate blood for money seemingly decreases their general willingness to donate - altruistically and non-altruistically ${ }^{19,20}$, although $\mathrm{cf}^{21}$. And finally, objections to commodification based on inequality concern the fact that the more things are commodified, the more important the difference between being rich and poor, which is usually considered (pro tanto) morally problematic not only by 
proponents of egalitarianism but also by a range of other normative theories, such as prioritarianism and utilitarianism.

With regard to semiotic objections, there appears to be no difference between TES and FAS. If these practices have the potential to change the meaning of terms such as donation, parenthood, and reproductive material, they seemingly have that potential to the same extent. I will therefore not go further into semiotic objections to TES and FAS. It is, however, worth noting that semiotic objections seem to presuppose that there is something morally problematic about changing meanings, which may not be the case at all. For instance, the practice of adoption has arguably changed the meaning of being a parent but it is not clear that adoption is, therefore, a morally bad thing. In any event, it is an open question whether it is good or bad that a certain practice changes meaning.

However, when it comes to the potential to crowd out altruistic practices, there does seem to be an important distinction between TES and FAS as only the latter has the potential to crowd out an altruistic practice, namely, altruistic egg donation. If potential donors can donate through FAS and receive a greater benefit than they can receive through (compensated) donation, they may naturally opt for the former instead of the latter. By contrast, donors engaged in TES would presumably not otherwise have chosen to donate their eggs. Even if they would, donors engaged in TES tend to be older and therefore often lack the quality of eggs required to be an egg donor.

However, it is worth mentioning here that the practice of altruistic egg donation has been subject to a great deal of moral controversy ${ }^{22}$. This is because altruistic egg donors are subjected to medical risks solely for the benefits of others, which some critics find morally problematic. Moreover, eggs are extremely lucrative for clinics. As some critics have remarked, why should the donor, who assumes all the risks, be the only one in the arrangement not getting paid ${ }^{10}$ ? With this in mind, it is at least not obvious that crowding out altruistic egg donation would be a bad thing, although this could potentially raise the price of fertility treatment.

What about inequality then? The more things are commodified, as opposed to distributed through other means, the greater the difference between being rich and being poor. Does FAS introduce more or less of this kind of inequality compared to TES? In this regard, there is seemingly no difference between FAS and TES. Both of these arrangements provide more eggs for women or couples with the resources to pay for fertility treatment, thereby increasing the difference between being rich and poor. However, it is worth noting that both arrangements also provide more opportunities for those who are relatively less well off, as they gain increased access to egg freezing and fertility treatment, respectively.

Based on the above, we can conclude that at least one worry related to commodification applies more readily to FAS than to TES, namely, that FAS may to a larger extent result in crowding out an altruistic practice. Thus, in this particular regard, and to the extent that this is truly morally bad or wrong, FAS can be considered more morally problematic than TES. As mentioned, however, it is far from obvious that crowding out altruistic egg donation would indeed be a morally bad thing, as this practice has been widely criticized for being unfair and harmful to donors. Let us, therefore, move on to the third traditional objection to TES. 


\section{Pressure}

The third traditional criticism of egg sharing is that it pressures women into giving away their eggs because they lack better alternatives. This objection is seemingly bolstered by the fact that people's willingness to engage in TES appears to be highly dependent on the availability of publicly funded fertility treatment ${ }^{23}$. That is, when publicly funded treatment is available, only few people in need of fertility treatment choose to engage in TES. On this background, it is often claimed that TES raises ethical concerns about autonomy and consent.

It seems beyond doubt that women could also feel some kind of pressure to engage in FAS. For instance, if they lack the required funds for freezing, it is not difficult to imagine that some women would experience some kind of pressure to share some of their eggs, as this would give them opportunities that they would not otherwise have had. This pressure could plausibly be exacerbated by a lack of opportunities to have a family early in life, for example, due to a lack of publicly funded child care and so on, which makes it difficult to have children before having established a career, at which point one's fertility has typically declined. It, therefore, seems safe to assume that donors engaging in FAS would do so on the background of some sources of pressure, whether purely due to a lack of funds or also a lack of possibilities for having children early in life.

However, there are a number of reasons to suppose that compared to TES, FAS is much less compromising when it comes to autonomy and consent. First, donors engaged in FAS have other options in terms of becoming pregnant. As mentioned, the practice of egg freezing is commonly seen as a back-up plan, and it is rarely the only option for women, despite any perceived or real societal pressure to postpone pregnancies. Whereas donors engaged in TES have no other options in the absence of publicly funded fertility treatment, this is not the case for donors engaged in FAS.

Second, donors engaged in FAS are not as pressured by a strong desire to have children as donors engaged in TES. After all, the latter are in the process of becoming pregnant through fertility treatment, whereas the former may not even be sure whether they want to have children. They may merely engage in FAS to keep their options open. To the extent that strong desires can miti-

gate consent, for example, by skewing perceptions of risks and reward, this applies much more readily to donors engaged in TES than donors engaged in FAS.

In sum, just as in the case of harm to donors, there are important morally relevant differences between TES and FAS when it comes to pressure and autonomy. That is, compared to FAS, TES has much greater potential to compromise autonomy and undermine consent. However, TES has not only been criticized for putting pressure on women, this practice has also been lamented for being exploitative, whether this concern also applies to FAS is the subject of the next section.

\section{Exploitation}

The fourth traditional criticism of TES is that this practice involves exploitation. The idea here is that those who are well off do not have to resort to egg sharing as they can pay for their fertility treatment themselves, whereas those who are worse off have to give up on some of their eggs to 
get the treatment they require. In essence, TES has been considered exploitative because it benefits those who are relatively better off, at the expense of those who are relatively worse off.

Can FAS be said to involve exploitation in the same way? Just as it has been the case with TES, it seems safe to assume that those who are relatively better off will not have to resort to FAS to have their eggs frozen as they can pay for the procedure themselves, whereas those who are worse off will have to give up on some of their eggs to enjoy the benefits of egg freezing. And similarly, it seems safe to say that FAS also benefits those who are better off, namely, those who can afford fertility treatment, at the expense of those who are worse off, namely, those who cannot afford egg freezing on their own. Nevertheless, as I will show in the following, there are a number of reasons to believe that FAS, at least in one sense, is less exploitative than TES.

There are many different conceptions of exploitation ${ }^{24,25,26}$, but for the present purposes, we can understand exploitation as someone taking an unfair advantage over others ${ }^{27}$. To expand a bit on this notion, exploitation can be understood as both involving taking advantage over others and using this advantage to unfairly skew the distribution of benefits and harms. To see this, consider the following. Suppose Anne is walking through a desert dying of thirst. Now suppose Beatrice comes along and offers her some water, on the condition that Anne pays her half her income for the rest of her life. This is clearly an instance of exploitation as Beatrice takes advantage of Anne's misfortune to gain a personal benefit. Had Anne not needed the water (been vulnerable), or had Beatrice not charged her anything for it (benefitted from this vulnerability), there would ceteris paribus not be a moral problem. In this way, exploitation can be understood as having two dimensions that can be more or less present. And this is key to understanding how FAS can be considered both less and more exploitative than TES, because donors engaged in FAS are presumably less vulnerable than donors engaged in TES, in the sense that the former has other opportunities available to them. Donors engaged in FAS, however, arguably receive far less benefit from FAS than donors engaged in TES.

With regards to vulnerability, there are couple of noteworthy differences between donors or couples engaged in TES and FAS. Perhaps most obviously, donors or couples engaged in TES are involuntary infertile and usually without other options in terms of getting fertility treatment. Of course, adoption may be an option for some, but not everybody wants to adopt and some people have difficulties adopting, for example, due to their sexual orientation. It is, therefore, perhaps difficult to understate the vulnerability involved in such unhappy circumstances. Indeed, people who desperately want children and lack available alternatives could be considered as prime candidates for being exploited. Donors engaged in FAS are not similarly influenced by strong desires and lack of alternatives.

On the other hand, donors engaged in FAS are presumably younger than donors engaged in TES. It is generally accepted that young people are more vulnerable than older people, either because they lack the maturity of age or simply because they generally tend to be worse off financially and thus have access to fewer alternatives than older people. In any event, it seems safe to assume that donors engaged in FAS are generally less vulnerable than donors engaged in TES, although the former tend to be younger than the latter. After all, the pressure experienced from involuntary childlessness can be immense. 
With regard to the distribution of benefits and harms, however, things appear to be the other way around. In this regard, donors engaged in TES appear to be much better off than donors engaged in FAS. This is primarily because, as explained, most women who freeze their eggs end up not using them ${ }^{28}$. Freezing is a back-up plan. This is certainly not the case with donors engaged in TES, who always receive the benefit of treatment after sharing their eggs. Of course, there are other benefits to having eggs stored in the freezer, such as peace of mind and decreased risk of future regret ${ }^{29}$. This may of course be important not only to individual women or couples but also to their families and relatives. However, having eggs stored in the freezer does not only give peace of mind, it also invites a number of unwelcome considerations, such as whether to continue paying for storage, whether to destroy or give away any surplus eggs, and so on.

Moreover, as opposed to TES, FAS involves recurrent payment for storage, further skewing the distribution of harms and benefits of FAS compared to TES. This is seemingly particularly problematic when clinics make a fortune on storage and fertility treatment, while donors receive little to no benefit. Hence, in this particular sense, FAS can be viewed as more exploitative than TES, because donors engaged in FAS often see little benefit considering the costs. This concern could of course be somewhat alleviated if clinics were allowed (and/or willing) to share a larger part of the profits resulting from the shared eggs, but as long as that is not the case, donors engaged in FAS appear to be worse off in this particular regard than donors engaged in TES.

However, even if donors engaged in FAS are worse off in this particular regard, they are not necessarily being exploited more than donors engaged in TES, as there is more to exploitation than receiving a poor share in a transaction. It is, therefore, not at all obvious that donors engaged in FAS are exploited more than donors engaged in TES. In one sense, it is rather the other way around.

\section{Conclusion}

In this paper, I have compared the moral merits of TES schemes with modern FAS schemes. As I have shown, although these practices may appear morally on par from the outset, this is not the case on further inspection. With regard to harm to donors, FAS appears to be much less harmful, as donors engaged in FAS (contrary to donors engaged in TES) do not have to give up on eggs that they could otherwise have used to become pregnant. When it comes to commodification, TES and FAS raise similar concerns about commodification, although only FAS has potential to crowd out an altruistic practice, namely, altruistic egg donation. Moreover, FAS is much less likely to compromise autonomy and undermine consent, as donors engaged in FAS are not under the same pressure to donate as donors engaged in TES, who have fewer (if any) alternatives to donating. Finally, FAS is potentially less exploitative in one way (preying on the vulnerable), and more exploitative in another (unfair distribution of benefits and harms).

This suggests, at least on a balance of reasons approach, that although FAS can in one way be seen as more exploitative than TES, it is, nevertheless, easier to justify from a moral perspective, as it also involves less harm to donors, less pressure with regard to informed consent, and less preying on the vulnerable. 
For all I have said here, however, it may of course still be the case that FAS is morally wrong. I have not argued anything to the contrary. What I have tried to defend here is the more modest claim that FAS and TES are not morally on par, and that FAS appears to be the better option (or the lesser evil), whether FAS is indeed a morally acceptable solution to the lack of donor eggs and equal access to egg freezing is another discussion.

\section{Acknowledgments}

I would like to express my very great appreciation to the Ice Age Research Group, as well as the Research Group for Criminal Justice Ethics at Roskilde University for reading and commenting on my work. In particular, I would like to extend a special gratitude to professor Thomas Søbirk Petersen for insightful and constructive comments.

\section{Funding}

This work was funded by the Independent Research Fund Denmark.

\section{Conflicts of interest}

The author has no competing interests.

\section{Ethical disclosures}

Protection of human and animal subjects. The author declares that no experiments were performed on humans or animals for this study.

Confidentiality of data. The author declares that no patient data appear in this article.

Right to privacy and informed consent. The author declares that no patient data appear in this article.

\section{References}

1. Dyer C. Payment to egg donors is to be tripled to remedy shortage. BMJ. 2011;343:d6865

2. Jones BP, Saso S, Mania A, Smith JR, Serhal P, Ben Nagi J. The dawn of a new ice age: social egg freezing. Acta Obstet Gynecol Scand. 2018;97:641-7.

3. Krawiec KD. Lessons from law about incomplete commodification in the egg market. J Appl Philos. 2016;33:160-77.

4. Ahuja K. Egg-sharing: as Relevant in Oocyte Freezing Today as in IVF Two Decades Ago. United Kingdom: BioNews; 2019.

5. Ethics Committee of the American Society for Reproductive Medicine. Financial compensation of oocyte donors: an ethics committee opinion. Fertil Steril. 2016;106:e15-9.

6. Cohen CB. New Ways of Making Babies: the Case of Egg Donation. United States: John Wiley \& Sons; 1996.

7. Blyth E, Golding B. Egg sharing: a practical and ethical option in IVF? Expert Rev Obstet Gynecol. 2008;3:465-73. 


\section{R. Klingenberg: New schemes, old ethics}

8. Haimes E, Taylor K, Turkmendag I. Eggs, ethics and exploitation? Investigating women's experiences of an egg sharing scheme. Soc Health IIIn. 2012;34:1199-214.

9. Goold I, Savulescu J. In favour of freezing eggs for non!medical reasons. Bioethics. 2009;23:47-58.

10. Kroløkke C, Petersen TS, Herrmann JR, Bach AS, Adrian SW, Klingenberg R, et al. The Cryopolitics of Reproduction on Ice: a New Scandinavian Ice Age. Bingley, United Kingdom: Emerald Group Publishing; 2019.

11. Ahuja KK, Simons EG, Mostyn BJ, Bowen-Simpkins P. An assessment of the motives and morals of egg share donors: policy of payments to egg donors requires a fair review. Hum Reprod. 1998;13:2671-8.

12. Scott R, Williams $C$, Ehrich $K$, Farsides B. Donation of spare fresh or frozen embryos to research: who decides that an embryo is spare and how can we enhance the quality and protect the validity of consent? Med Law Rev. 2012;20:255-303.

13. Waldby C. The Oocyte Economy: the Changing Meaning of Human Eggs. United States: Duke University Press; 2019.

14. Baldwin K, Culley L, Hudson N, Mitchell H. Running out of time: exploring women's motivations for social egg freezing. J Psychosom Obstet Gynecol. 2019;40:166-73.

15. Sandel MJ. What money shouldn't buy. Hedgehog Rev. 2003;5:77-98.

16. Anderson ES. Why commercial surrogate motherhood unethically commodifies women and children: reply to McLachlan and Swales. Health Care Anal. 2000;8:19-26.

17. Satz D. Why Some Things Should Not Be for Sale: the Moral Limits of Markets. New York: Oxford University Press; 2010.

18. Brennan J, Jaworski PM. Markets Without Limits: moral Virtues and Commercial Interests. United Kingdom: Routledge; 2015.

19. Titmuss R. The gift of blood. Trans Action. 1971;8:18-26.

20. Ten Have HA, Welie JW. Ownership of the Human Body: philosophical Considerations on the Use of the Human Body and its Parts in Healthcare. Vol. 59. Berlin, Germany: Springer Science and Business Media; 2013.

21. Lacetera N, Macis M, Slonim R. Economic rewards to motivate blood donations. Science. 2013;340:927-8.

22. Brandt R, Wilkinson S, Williams N. The Donation and Sale of Human Eggs and Sperm. California: The Stanford Encyclopedia of Philosophy; 2017.

23. Pennings G, Autin C, Decleer W, Delbaere A, Delbeke L, Delvigne A, et al. Cross-border reproductive care in Belgium. Hum Reprod. 2009;24:3108-18.

24. Marx K. Capital: volume One. United States: Courier Dover Publications; 2019.

25. Locke, J. Locke: Political Essays (Cambridge Texts in the History of Political Thought) (M. Goldie, Ed.). Cambridge: Cambridge University Press; 1997.

26. Valdman M. A theory of wrongful exploitation. Philos Impr. 2009;9:1-14.

27. Zwolinski M, Wertheimer A. Exploitation. California: The Stanford Encyclopedia of Philosophy; 2017.

28. Hammarberg K, Kirkman M, Pritchard N, Hickey M, Peate M, McBain J, et al. Reproductive experiences of women who cryopreserved oocytes for non-medical reasons. Hum Reprod. 2017;32:575-81.

29. Mertes H. Does company-sponsored egg freezing promote or confine women's reproductive autonomy? J Assist Reprod Genet. 2015;32:1205-9. 